\title{
Reevaluating the Grandmother Hypothesis
}

\author{
Aja Watkins \\ Forthcoming in History and Philosophy of the Life Sciences, July 2021
}

\begin{abstract}
Menopause is an evolutionary mystery: how could living longer with no capacity to reproduce possibly be advantageous? Several explanations have been offered for why female humans, unlike our closest primate relatives, have such an extensive post-reproductive lifespan. Proponents of the so-called "grandmother hypothesis" suggest that older women are able to increase their fitness by helping to care for their grandchildren as allomothers. This paper first distinguishes the grandmother hypothesis from several other hypotheses that attempt to explain menopause, and then develops a formal model by which these hypotheses can be compared and tested by empirical researchers. The model is then modified and used to respond to a common objection to the grandmother hypothesis: that human fathers, rather than grandmothers, are better suited to be allomothers due to their physical strength and a high incentive to invest in their own children. However, fathers - unlike maternal grandmothers - can never be sure that the children they are caring for are their own. Incorporating paternity uncertainty into the model demonstrates the conditions under which the grandmother hypothesis is more plausible than a hypothesis that focuses on the contributions of men.
\end{abstract}

Humans are different from our primate relatives. Many researchers like to posit the thing that makes humans unique - language, culture, cooking, cooperative behavior. These qualities are meant to explain what has made humans so successful compared to other species.

Some theorists have focused in particular on the unique features of human life histories. One such feature is our long childhood and adolescence; by some estimates, a human requires nearly 14 million calories to be provided to her by others before she is nutritionally self-sufficient (Kaplan, 1994). Compared to other great apes, which are nearly self-sufficient when weened, human adolescence presents a crucial opportunity for learning specialized skills which contribute to the survival prospects of adults. Another unusual feature about human life histories is that women have long post-reproductive lives. Not 
only is this not the case for other primates, who die naturally of old age after their childbearing years, it is also an evolutionary mystery. What is the purpose of living with no potential to reproduce?

One possible answer, the grandmother hypothesis, uses considerations of inclusive fitness and kin selection to connect these two features of human life histories. Postmenopausal women, the hypothesis goes, serve a crucial role in the rearing of their grandchildren. Section 1 of this paper lays out the details of the grandmother hypothesis in depth. Section 2 presents a model of the grandmother hypothesis, which provides a precise means of delineating the different hypotheses for the emergence of menopause. Additionally, the model should enable empirical researchers to test the grandmother hypothesis against these other explanations for women's post-reproductive longevity.

Section 3 uses that model to respond to an objection to the grandmother hypothesis. The objection amounts to questioning why the grandmother hypothesis focuses on grandmothers, rather than other potentially important allomothers such as older sisters, aunts, or, especially, fathers. My response will consist of pointing out how maternal grandmothers are uniquely well-situated to care for their grandchildren. Ultimately, addressing this objection will give empirical researchers tools by which to evaluate the plausibility of the evolution of allomothering behavior in grandmothers or in fathers.

By specifying the empirical conditions under which different evolutionary hypotheses are more or less plausible, this paper provides guidance to scientists. The model developed herein also helps to provide conceptual insight into the grandmother hypothesis and other alternative explanations of the evolution of menopause. Conceptual insight and guidance to scientists are both tasks for philosophers of science, and this paper contributes to that tradition. This paper also contributes to another tradition within feminist philosophy of science, though. Feminist philosophers of science have been concerned with whether and to what extent traits of human men versus human women have been the primary drivers of human evolution - and whether any of these traits have been systematically overlooked (classic examples include Bleier, 1984, Keller, 1992, and Anderson, 1995). This 
paper contributes to this literature by highlighting some of the ways in which the specific traits of human females - in this case, maternity certainty - have been overlooked or undervalued by evolutionary theorists.

\section{The grandmother hypothesis}

Relying on alloparents can increase the expected number of one's offspring that will survive to adulthood. Alloparents can contribute in two ways: (1) reducing the interbirth interval by allowing mothers to ween their young earlier than they would be able to otherwise, and (2) increasing the chances of survival of young by helping the mother provide for them or protect them. Option (2) can also include teaching the young how to take care of themselves, either now or as future adults. However, sharing care with others, even relatives, can be dangerous. A mother has to be able to trust that the allomother will provide adequate care, including nutrition, and won't take advantage of an opportunity to harm the infant (which can be beneficial to the perpetrator when resources are scarce). Balancing the benefits with the risks of alloparenting has led some primates, including human mothers, to rely on alloparenting substantially, while other primate mothers take on sole responsibility for rearing their young. It is relatively easy to see evidence for reliance on alloparenting in humans: unlike in many other mammal species, including our closest primate relatives, human mothers are willing to share care of their children with others, especially family members (Hrdy, 2009).

Allomothers can include father: 1 , siblings, aunts and uncles, cousins, grandparents, and even non-relatives. Having more rather than fewer alloparents will likely be better for a human mother and her child; indeed, alloparenting may have been crucial to enabling the long, resource-intensive adolescence so essential to human development, as well as the short interbirth interval of about three years not seen in other primates (e.g., Hawkes et al. 2000, p. 243). However, alloparenting, in combination with considerations of inclusive

\footnotetext{
${ }^{1}$ Technically, fathers aren't alloparents; they are allomothers.
} 
fitness and kin selection, is also thought to explain a particular evolutionary mystery: menopause.

Menopause is evolutionarily confusing because, normally, selection occurs to increase lifespans when doing so increases reproductive potential. (Thus longevity is the same as any other trait on which selection can operate.) When a woman lives past menopause, she is getting older without any potential for having more children. It is a misconception to think that women today only live past menopause because life expectancy of humans is greater than it was during our evolutionary history (e.g., Fausto-Sterling, 1992, p. 178). The primary reason life expectancy was so low in the past was due to high rates of death at a young age, not due to earlier deaths as a result of aging. The age of senescence, when the body starts to naturally deteriorate and ultimately die, hasn't changed for humans in recent evolutionary history (see, e.g., Hawkes \& Blurton Jones, 2005; Caspari \& Lee, 2004). However, female reproductive capability ceases at around the same time in humans as in other primates. Humans are thus unique among primates for our significant post-reproductive lives.

I should note that the picture is more complicated than this: Paul (2005) provides a good overview of evidence of post-reproductive lifespans in non-human primates, and Hrdy (2009) offers several examples of non-human grandmothering behavior. For the purposes of this paper, though, I will take it as noncontroversial that the sheer extent of post-reproductive productivity in humans is unique among primates (see, e.g., Herndon, 2009).

It is, of course, possible that menopause or the following post-reproductive years are not adaptive, and have merely emerged as a result of drift or other non-selective pressures, including possibly as a by-product. I will address non-adaptationist explanations later, but first I will address the three main hypotheses for why menopause might be adaptive. The first hypothesis, the "stopping early hypothesis," imagines that human women used to be reproductive for the entire length of our current lifespans (about 75 years), but that it became advantageous to stop reproducing earlier than that (e.g., Williams, 1957). 
For instance, the risks of late pregnancies to the mother could have made it beneficial for women to stop reproducing earlier. Most important for this paper is that the fitness benefits conferred by expending energy elsewhere - namely, on caring for existing children or grandchildren - may have been higher than the fitness benefits of continued reproduction. Hawkes and Smith (2010) criticize the stopping early hypothesis for inadequately explaining why nonhuman primates, which also require postnatal care, would not have evolved such a productive post-menopausal lifespan.

A second hypothesis, the "extended mothering hypothesis," suggests that an elongated post-reproductive life, and therefore delayed senescence, would have been selected for insofar as longer-lived mothers would be able to continue to care for their offspring; until a woman's last dependent child has reached independence, her parenting work isn't finished (e.g., Peccei, 2001). The extended mothering hypothesis, unlike the stopping early hypothesis, does not say that our reproductive lives got shorter, but that our total lives got longer, by adding a post-reproductive period. Given that the reproductive lifespans of other great apes is roughly the same as those of human women (about 40 years), some say that it makes more sense to think that our ancestors also had such a reproductive lifespan, rather than one that matches our current total lifespans (e.g., Hawkes, 2003).

Instead of focusing on the benefits of prolonged mothering, proponents of the "grandmother hypothesis" suspect that grandmothers played a crucial role in the success of their grandchildren (e.g., see Hawkes, O'Connell, \& Blurton Jones, 1989; Hawkes, O'Connell, Blurton Jones, Alvarez, \& Charnov, 1998, O'Connell, Hawkes, \& Blurton Jones, 1999; Hawkes, 2003; Hawkes, 2004a; Hawkes, O'Connell, \& Blurton Jones, 2018), A grandmother's inclusive fitness includes the fitness of her grandchildren, so if a grandmother can do more good than harm for the fitness of her progeny by staying alive and not reproducing, genes that facilitate this post-reproductive period will propagate. Like the extended mothering hypothesis, the grandmother hypothesis doesn't say that human women shortened their reproductive lifespan, but that they elongated their total lifespan. The

\footnotetext{
${ }^{2}$ For a model that combines post-menopausal mothering and grandmothering, see Peccei 2005 p. 53).
} 
difference between the grandmother hypothesis and the extended mothering hypothesis is that the grandmother hypothesis says it's a woman's contribution as a grandmother, rather than as a mother, that caused the post-reproductive lifespan to be selected for.

Empirical evidence regarding the grandmother hypothesis, which quantifies the benefit that grandmothers have relative to other allomothers, is summarized in Mace and Sear (2005, p.147). The original observations which led to the grandmother hypothesis were of Hadza maternal grandmothers in Tanzania (Hawkes et al., 1989). There may also be (preliminary) genetic evidence in favor of the grandmother hypothesis (Hawkes, 2016). Hawkes et al. (1998, p. 1338-1339) propose three possible time periods in which grandmothering behavior could have evolved in humans: 1.8 million years ago, when Homo erectus originally appeared, around 600,000 years ago, with the emergence of early archaic humans, or 50,000 years ago, when humans became behaviorally modern.

The benefits of a grandmother's alloparental effort will be the same as for any allomother: reducing the interbirth interval between her grandchildren, and increasing their chances of survival. Grandmothers (or any alloparents) facilitate these ends by supervising grandchildren, so that mothers can perform other tasks like food collection more efficiently; provisioning for grandchildren, thereby reducing the nutritional burden on mothers (including, possibly, allowing children to be weened sooner); and educating grandchildren, so that they are more productive themselves. If grandmothers are self-sufficient - namely, if they are able to produce more food than they consume - the costs of longevity will be outweighed by the benefits of the grandmother staying alive. It is thus very easy to see how it would be evolutionarily advantageous for a grandmother to live longer and be an alloparent for her grandchildren, rather than die at the end of her reproductive lifespan.

However, it is more difficult to see why it could be more advantageous for a grandmother to live longer post-reproduction than for her to live longer and just keep reproducing. (Note that the extended mothering and the stopping early hypotheses face the same problem.) One thought, mentioned above, is that it becomes riskier for mothers to birth children as they get older. Another thought is that having too many children is 
disadvantageous because they will compete with each other for resources and none will end up sufficiently resourced. However, these are not sufficient explanations: a child, which will share $50 \%$ of the mother's DNA, is twice as good fitness-wise as a grandchild, so the risk to the children (or, conversely, the benefit to the grandchildren) would have to be proportionately substantial for the grandmother to be better off tending to her grandchildren than attempting to have her own children. In order to test the feasibility of the grandmother hypothesis, it is necessary to compare the fitness benefits of grandmothering behavior with that of continued reproduction (see section 2).

One common objection to the grandmother hypothesis is that insofar as it relies on the benefits of maternal grandmothers $3^{3}$ it requires that adult daughters and their mothers reside locally, i.e., that the society is matrilocal. In patrilocal societies, in which males reside with their kin but females migrate to other groups to procreate, the presence of a maternal grandmother would be unlikely Hrdy (2009) effectively rebuts this objection by arguing, first, that the evidence for human patrilocality before property ownership became important is questionable, and, second, that grandmothers may have been able to respond to the relocation of their daughters by relocating as well. She attributes the assumption that human societies are patrilocal to "entrenched assumptions about the patrilocal tendencies of all hominid apes" and "a tendency to project onto early Paleolithic ancestors patriarchal attributes from later time periods" (p. 239)

Some mistakes have been made by grandmother hypothesis proponents. First, grandmothering is not a matter of trading "quality" for "quantity" of offspring (cf. Peccei, 2005, p. 38). Evolution operates on the number of offspring, and improving "quality," i.e., survival rates or reproductive capacity, of offspring is only a means to increasing the quantity of descendants down the line. Second, it can't be the case that continued child-

\footnotetext{
${ }^{3}$ Of course, nothing I have said so far requires that the grandmother hypothesis is about maternal grandmothers, but early literature on the grandmother hypothesis does tend to focus on the role of maternal grandmothers in particular. Why this might be is the subject of section 3 .

${ }^{4}$ This explains the matrilocality of toothed whales, species which also exhibit post-reproductive grandmothering behavior (e.g., Johnstone \& Cant, 2010; Ward et al., 2009).

${ }^{5}$ Hrdy (1989) also says, "what if patrilocal residence patterns did not reflect million-year-old lifestyles so much as demographic and historical trends of the last tens of thousands of years?" (p. xxv).
} 
bearing ceased because it was interfering with grandmothering (cf. Hawkes et al., 2000, p. 241). Assuming that both an elongated reproductive lifespan and a productive but post-reproductive one are viable options, then which one evolved is a matter of which was more advantageous overall; it is not a valid answer to the question "why didn't human women simply evolve longer reproductive lifespans?" to say "because then they couldn't be good grandmothers."

In addition to the three adaptationist hypotheses, there are two candidate explanations for menopause that do not posit that it confers a fitness benefit per se. First, as Hawkes et al. 1998, 2000) readily admit, a longer average adult lifespan typically corresponds with a delay in age to fertility; duration of childhood divided by average adult lifespan is approximately invariant (Charnov, 1993) ${ }^{6}$. The grandmother hypothesis is not incompatible with the view that an extended human adolescence was selected for due to its educational opportunities (cf. Sterelny, 2012, p. 80). The advent of grandmotherhood, which would have been especially beneficial to children who were dependent for longer durations, may have contributed to the lengthening of these adolescent periods in turn, creating a selfreinforcing feedback loop. Similarly, Hrdy (2005, p. 303) says: "long 'childhoods' could be a corollary of cooperative provisioning that happened to reduce pressures on young to grow up fast or starve by allowing Darwinian selection to favor larger, slower growing ape-quality brains without incurring the otherwise prohibitive costs." However, this "life history invariance hypothesis" does say that it is not the extended post-reproductive period per se that is selected for; rather, that it emerged as a side effect of selection on longer childhoods.

A second non-adaptationist hypothesis is the "anatomical invariance hypothesis." Perhaps there are anatomical reasons why the human female reproductive lifespan cannot be more than 40 or so years (as suggested in, e.g., Hawkes, 2003, p. 389; Voland et al., 2005 , p. 3; Peccei, 2005, p. 45, 49; and Huber \& Fieder, 2018). Insofar as "slower senescence

\footnotetext{
${ }^{6}$ See Alvarez (2000) for a comprehensive discussion of life history theory pertaining to the grandmother hypothesis.
} 
generally comes at the cost of reduced fertility at younger ages," for example, there may have been strong selection pressure to keep females' reproductive life cycles the way they were, while still delaying senescence (Hawkes et al., 2000, p. 239). Note that this hypothesis does require that we give an adaptationist account of the delay of senescence, and one that does not appeal to the fitness benefits of extended mothering or grandmothering. For instance, we might say that there was selective pressure on males to live longer (and thereby reproduce more), and that delayed senescence in females is merely a byproduct which, for whatever reason, could not be accompanied by continued reproduction.

I will not directly argue against these non-adaptationist explanations of menopause in this paper. However, in section 2, I will compare the view that grandmothering (or extended mothering) does confer a fitness benefit to the view that it does not. I will thus be considering the two non-adaptationist hypotheses insofar as they both claim that grandmothering does not confer a significant fitness benefit.

In summary, there are five candidate hypotheses explaining post-reproductive lifespans in human women:

1. Adaptationist hypotheses:

(a) Stopping early hypothesis: Human women began to stop reproducing earlier, without shortening their total lifespans, due to some fitness benefit (cost) of (not) doing so.

(b) Extended mothering hypothesis: Human women began to live longer, past their reproductive lifespans, due to the fitness benefit of caring for their youngest children until they were independent.

(c) Grandmother hypothesis: Human women began to live longer, past their reproductive lifespans, due to the fitness benefit of caring for their grandchildren as allomothers.

2. Non-adaptationist hypotheses:

(a) Life history invariance: As human adolescence got longer, total human lifespans got longer as a side effect, although living longer did not confer any fitness benefit in itself.

(b) Anatomical invariance: For unknown reasons, it is anatomically impossible for human women to have longer reproductive lifespans. When there was selective pressure on delayed senescence in humans, it did not delay reproductive senescence in women. 
In section 2, I will develop a model that allows for explicit comparison between the adaptationist hypotheses and the generic non-adaptationist hypothesis that says that the extended post-reproductive lifespan in human women is not adaptive. Then, in section 3 , I will use the model to respond to a common objection to the grandmother hypothesis.

\section{Modeling the grandmother hypothesis}

Mathematical models of the grandmother hypothesis have had mixed results: Kachel, Premo, and Hublin (2011) found that the inclusive fitness benefits were too small to change human life history variables, but Kim, Coxworth, and Hawkes (2012), Kim, McQueen, Coxworth, and Hawkes (2014), Chan, Hawkes, and Kim (2016), Kim, McQueen, and Hawkes (2019), and Paquin, Kato, and Kim (2020) found that grandmothering was sufficient to do so. However, some of the assumptions used in these previous models are problematic.

Kachel et al. (2011) developed an agent-based model to test the grandmother hypothesis, but the model assumes that "the total reproductive potential of each female is finite and conserved" such that changes in the length of a reproductive period can "only affect the way in which fertility is distributed over a female's lifetime, not the maximum number of offspring she can expect to have under idealized conditions" (p. 385). This is a problematic assumption because the potential benefit of a delayed reproductive senescence is exactly that it would increase one's total reproductive potential. Decreasing the interbirth interval should also be able to increase total reproductive potential. Kachel et al. (2011, p. 386) also assume that grandmothers cannot help their grandchildren if they still have dependent children of their own, which I think is intuitively unwarranted.

Kim et al. (2012, 2014), Chan et al. (2016), Kim et al. (2019), and Paquin et al. (2020) are all different iterations of the model originally developed in Kim et al. (2012), and so they share many of the same assumptions. The model in Kim et al. (2012) is a deterministic model in which individuals move through several life stages at fixed ages: 
unweaned, weaned dependent, independent juvenile, fertile, post-fertile, and eventually frail. Fertile females can only reproduce if they are not currently responsible for any dependents. Post-fertile females who are not yet at the frailty stage are able to assume care of any weaned dependent, not just their descendants, which effectively increases the birthrate for the fertile females whose children are being cared for by post-fertile females. Kim et al. (2014)'s model is an agent-based model that uses these same assumptions, as does the ordinary differential equations model in Paquin et al. (2020). The differential equations-based model in Chan et al. (2016) and the agent-based model in Kim et al. (2019) use the same assumptions, but restrict grandmothering to matrilineal descendants, which more adequately captures the grandmother hypothesis, and allowed age at last birth and total lifespan to evolve. All of these models found that grandmothering was sufficient to cause the emergence and maintenance of menopause in female life histories. However, some of these assumptions are unrealistic: namely, that grandmothers can care for any child, not just their progeny, which is present in Kim et al. (2012, 2014) and Paquin et al. (2020), but also, for example, a constant weaning age and inability to reproduce while caring for weaned dependents, which is present in all models. Although the authors argue that these assumptions would actually make it less likely for grandmothering to lead to the evolution of menopause, I would prefer a model that just did not incorporate these objectionable assumptions.

The model that I propose below also has a different purpose or aim than the models developed by Kachel et al. (2011), Kim et al. (2012, 2014), Chan et al. (2016), Kim et al. (2019), and Paquin et al. (2020). Existing models of the grandmother hypothesis are intended to be tests of the grandmother hypothesis itself: is it plausible, mathematically, that the presence of helpful grandmothers could lead to the evolution of menopause? The model I propose has a different aim: to give the empirical conditions under which different candidate hypothesis to explain the evolution of menopause are more or less plausible. In service of this aim, the model I propose aspires to capture as simply as possible exactly what the grandmother hypothesis (as compared to other hypotheses) says: that the fitness 
benefits of grandmothering during a post-reproductive lifespan were enough to select for delayed senescence. The model should be able to compare the grandmother hypothesis to the extended mothering hypothesis, as well as other competitors. The benefit of using a simple model to compare the hypotheses is that it is clear to empirical researchers for which variables, exactly, we need to collect data, and how such data will be able to lend plausibility to some hypotheses over others.

Most models of alloparenting involve Hamilton's (1964) rule for inclusive fitness: $c<$ $r b$, where $c$ is cost to the alloparent, $r$ is degree of relatedness between the offspring and the alloparent (e.g., 0.25 between an aunt and her sibling's child), and $b$ is the benefit to the offspring. If $c<r b$, then we can expect the alloparenting behavior will occur; otherwise, it will not. Likewise, in the context of the grandmother hypothesis, authors often describe it as being about the inclusive fitness benefits of grandmothering.

For grandmothers, though, as for biological parents, considering inclusive fitness in the context of alloparenting only involves only direct, rather than indirect, fitness, in the sense that one only has to look at the benefits to the grandmothers' direct descendants.7 We can measure fitness by just counting the number of descendants a person has in a particular generation. I will be counting the expected (or average) number of grandchildren who survive to adulthood as a measure of a person's fitness.

First, I'll define some variables. Initially, let $n$ be the expected number of offspring a randomly selected woman from a particular population has, split up into $n_{f}=\frac{n}{2}$ for expected female children and $n_{m}=\frac{n}{2}$ for expected male children. The expected number of offspring for a man is also $n$ (this will be trivially true in a population that exclusively reproduces among themselves). Let $p$ be the average survival rate of a child, i.e., the probability that child will survive to adulthood. Each parent will have $n p$ children survive to adulthood.

\footnotetext{
${ }^{7}$ This terminology is inspired by West, Griffin, and Gardner (2007), although their definitions are slightly different. For example, they define indirect fitness as "the component of fitness gained from aiding related individuals," which would apply to helping grandmothers. Rather, my use of direct and indirect is meant to distinguish between direct descendants (children, grandchildren) and other relatives.
} 
In particular, we are interested in the number of adult grandchildren that a grandmother can expect to have. In a baseline scenario with no alloparenting, this will be

$$
g_{0}=n^{2} p^{2}
$$

Here is another scenario: women can lengthen their lives by some amount of time $t$ and continue to reproduce. This will have the effect of increasing $n$ by some number of additional children $x$. Of $x$, assume half are male and half are female. The sons' expected number of children will not increase, but the daughters' will also increase by $x$. (Note that it now must be the case that some women are reproducing with males outside the population for which I am computing the averages - otherwise, the expected number of children for males and females has to be the same.) This will result in the grandmother's expected number of adult grandchildren being:

$$
g_{1}=\left(n_{f}+\frac{x}{2}\right)(n+x) p^{2}+\left(n_{m}+\frac{x}{2}\right) n p^{2}=\frac{n+x}{2}\left((n+x) p^{2}+n p^{2}\right) .
$$

Call $g_{1}$ the fitness for scenario 1 .

Scenario 1 models the non-adaptationist hypotheses considered in section 1 (the life history invariance and anatomical invariance hypotheses), although it is agnostic about which if either of the two specific hypotheses I discussed is the correct one. If the fitness produced by scenario 1 turns out to be the highest (compared to the scenarios described below), then that means it won't have been adaptive for women to live longer and cease reproducing; if they had the option of living longer, their fitness would have been higher if they had kept reproducing during that time. Because menopause does actually occur, this means there is some other, non-adaptationist explanation for why women's postreproductive lifespans evolved, and why we can't continue to reproduce during that time.

Scenario 2 will match the extended mothering hypothesis. Mothers can again lengthen their lives by $t$, but now they do not continue to reproduce. Instead, they care for their existing children. This will have the effect of increasing $p$, say to $q$ where $q>p$. Daughters, 
in turn, will similarly live longer and care for their children, which will increase each $p$ to $q>p$. Sons' children will be unaffected by the change. This will result in a fitness of the grandmother of:

$$
g_{2}=n_{f} n q^{2}+n_{m} n q p=\frac{n}{2}\left(n q^{2}+n q p\right)
$$

Scenario 3 will match the grandmother hypothesis. Like scenarios 1 and 2, grandmothers will be able to live longer by $t$, and, like scenario 2, they will not reproduce. However, they will instead help their daughters raise their grandchildren (and, likewise, will be helped by their own mothers in raising their children). As explained in section 1, there are basically two ways that grandmothers can help. Note that I will not be representing the fitness of the first grandmother to help her daughters, but rather of a grandmother in a lineage of helping grandmother: 8 . First, in scenario 3a, they can reduce the interbirth interval for their daughters, increasing the number of grandchildren they can have, say by $y$. This will yield a fitness of:

$$
g_{3 a}=\left(n_{f}+\frac{y}{2}\right)(n+y) p^{2}+\left(n_{m}+\frac{y}{2}\right) n p^{2}=\frac{n+y}{2}\left((n+y) p^{2}+n p^{2}\right) .
$$

Notice that $g_{3 a}$ is identical to $g_{1}$, replacing $y$ for $x$. Second, in scenario 3b, grandmothers can increase the survival rate for their grandchildren, say to $s>p$. This will yield a fitness of:

$$
g_{3 b}=n_{f} n s^{2}+n_{m} n s p=\frac{n}{2}\left(n s^{2}+n s p\right),
$$

which is analogous to $g_{2}$. One could combine scenarios $3 \mathrm{a}$ and $3 \mathrm{~b}-$ such that grandmothers

\footnotetext{
${ }^{8}$ The model could be easily modified to represent the fitness of a "first generation" grandmother whose mother did not herself help out as a grandmother. In this case only the term pertaining to the grandchildren would differ from the baseline scenario. One way to accomplish this modification would be to examine four generations, rather than three: the first generation (and any earlier generations) would not have the grandmothering trait, but the second and subsequent generations would. Women in the second generation thus would not be helped by their own mothers, but women starting in the third generation would be. This model would be better able to address questions of the initial appearance of the grandmothering trait.
} 
are both reducing their daughters' interbirth interval and increasing their grandchildren's survival rate - to result in the following fitness:

$$
g_{3}=\left(n_{f}+\frac{y}{2}\right)(n+y) s^{2}+\left(n_{m}+\frac{y}{2}\right) n s p=\frac{n+y}{2}\left((n+y) s^{2}+n s p\right) .
$$

I will not have a scenario that matches the stopping early hypothesis. The stopping early hypothesis is only incompatible with the extended mothering or grandmother hypotheses in its initial conditions - the stopping early hypothesis requires that ancestral lifespans were the same as current lifespans, but that reproductive lifespans used to be longer for women than they currently are. Thus scenarios 2 and 3 could accommodate the stopping early hypothesis insofar as the stopping early hypothesis also posits some benefit to a post-reproductive lifespan. Instead of conceiving of scenarios 2 and 3 as adding to the total lifespans, they would be subtracting from the reproductive lifespans, without subtracting from the total lifespans. Similarly, scenario 1 would be more like the ancestral condition, and what I have called the baseline scenario would involve shortening the total lifespan (and, with it, the reproductive lifespan). For simplicity, I will hereafter ignore the stopping early hypothesis and focus on comparing the other hypotheses that match up with scenarios 1-3.

The fitness for each scenario can be compared to the others. In all of scenarios 1, 2, and 3 , it is clear that $g_{1}, g_{2}, g_{3 a}, g_{3 b}, g_{3}>g_{0}$. This was by design; each scenario increased the fitness from the baseline scenario in some way. It is also straightforward to compare scenarios 1 with $3 \mathrm{a}$ and 2 with $3 \mathrm{~b}: g_{3 a}>g_{1}$ when $y>x$, and $g_{3 b}>g_{2}$ when $s>p$. The comparisons between each scenario are summarized in table 1. For researchers interested in the grandmother hypothesis in particular, the last row of the table - circumstances in which $g_{3}$ is greater than the other fitnesses - is especially important.

It is an empirical question where these thresholds actually are and what sorts of increases in life expectancy and decreases in interbirth interval post-reproductive grandmothers are able to achieve, compared to what fitness benefits they could achieve by 
continuing to reproduce or caring for their own children as longer-lived mothers. Definitive support for the theory that grandmothering was more advantageous than other alternatives hinges on figuring out on what side of these thresholds our ancestors would have been situated. In any case, I take proponents of the grandmother hypothesis to be claiming that the threshold conditions hold which make scenario 3 (or, possibly, $3 \mathrm{a}$ or $3 \mathrm{~b}$ ) preferable to scenarios 1 and 2. My hope is that this model will aid empirical researchers in determining whether their observations lend support to the grandmother hypothesis, or any of the other hypotheses explicated in section 1. The use of these thresholds may be useful to researchers in other ways, as well. For example, the model suggests that researchers should focus their efforts on gathering data for particular variables: number of children and their survival rates. Additionally, some threshold conditions may be easier to evaluate than others; perhaps $g_{1}$ and $g_{3 a}$, and $g_{2}$ and $g_{3 b}$ should be compared to each other first, as these comparisons have the most straightforward threshold conditions, before either of $g_{1}$ or $g_{2}$ is compared to $g_{3}$. These more straightforward comparisons do not preclude the more complex comparisons - each of the hypotheses is potentially more likely than any of the others, making pairwise comparison necessary - but it may help to narrow down areas for further research to start with the simplest cases.

\begin{tabular}{|c||c|c|c|c|c|c|}
\hline & Baseline & Non-adaptationist & Extended Mothering & \multicolumn{3}{|c|}{ Grandmother Hypothesis } \\
\hline & $g_{0}$ & $g_{1}$ & $g_{2}$ & $g_{3 a}$ & $g_{3 b}$ & $g_{3}$ \\
\hline \hline$g_{1}$ & $x>0$ & - & - & - & - & - \\
\hline$g_{2}$ & $q>p$ & $x<\frac{n q-n p}{p}$ & - & - & - & - \\
\hline$g_{3 a}$ & $y>0$ & $y>x$ & $y>n\left(\frac{q}{p}-1\right)$ & - & - & - \\
\hline$g_{3 b}$ & $s>p$ & $s>\frac{p(n+x)}{n}$ & $s>q$ & $y<\frac{n s-n p}{p}$ & - & - \\
\hline$g_{3}$ & $y>0$ & if $y>x:$ always & if $s>q:$ always & $s>p$ & $y>0$ & - \\
& $s>p$ & if $y \leq x: s \geq \frac{p(n+x)}{n+y}$ & if $s \leq q: y \geq n\left(\frac{q}{s}-1\right)$ & & & \\
\hline
\end{tabular}

Table 1: Pairwise comparisons of when $g_{i}$ (row) is greater than $g_{j}$ (column). Redundant entries are not displayed. All scenarios other than the baseline have threshold conditions under which they are more or less plausible than the other scenarios. $n$ is the expected number of offspring in the baseline scenario; $x$ is the added number of offspring in Scenario $1 ; y$ is the added number of offspring in Scenarios 3a and 3; $p$ is the survival rate of offspring in the baseline scenario; $q$ is the survival rate of offspring in Scenario $2 ; s$ is the survival rate of offspring in Scenarios $3 b$ and 3. 
Of course, one might think that, prior to empirical investigation, we may be able to reason through which of these scenarios are most likely. For example, it may be unlikely that $s$, the survival rate of grandchildren due to grandmothering, is greater than $q$, the survival rate of grandchildren merely due to extended mothering, perhaps because we tend to think that mothers are more effective than grandmothers or because mothers merely have fewer children than grandmothers have grandchildren. If this were the case, we could rule out that $g_{3 b}>g_{2}$, i.e. that the grandmother hypothesis (or, at least the version of it that depends on increased survival rates of grandchildren) is more likely than the extended mothering hypothesis. However, note that the effort involved in childcare can take advantage of "economies of scale," such that a very small amount of additional effort is required per added child once one is already involved in supervising a group of children. So, it is not so obvious whether or to what extent grandmothers will be better or worse than mothers at increasing the survival rate of the children in their care - and it is exactly this question which will help to compare scenarios 2 and 3b. Therefore, I am more inclined to recommend rigorous empirical work on establishing which of these inequalities hold, rather than making even very educated guesses about them. Furthermore, as is apparent in table 1, although a comparison between $g_{3 b}$ and $g_{2}$ is relatively straightforward, a comparison between $g_{3}$ and $g_{2}$ is less simple. Especially for these more complex inequalities, I would hesitate to trust our intuitions about whether or not the inequalities hold, rather than studying them empirically. Researchers should instead use the results of the model, which provides the exact empirical information we need in order to settle the debate between the various hypotheses.

I would like to point out two assumptions I am making that could be altered to develop slightly more complicated models. First, it would be more accurate to represent fitness in number of grandchildren produced per unit time; there should be a fitness detriment to extending one's life. The model could easily accommodate this alteration by dividing all fitnesses by the total lifespan of the grandmother: $L$, say, in the baseline scenario, and $L+t$ in all other scenarios. This factor will be irrelevant for comparing scenarios 
$1-3$, because I have prescribed that $t$ is the same in all these cases, but it would enable meaningful comparison with the baseline scenario, which right now is just stipulated to result in a lower fitness than the other scenarios.$^{9}$ These comparisons may enable us to explain, for instance, why other primates do not have a post-reproductive or even elongated reproductive lifespan. I have not included this modification in the present analysis for the simple reason that my interests are more in comparing the non-baseline scenarios with one another, rather than comparing them to the baseline. However, other researchers with other purposes in mind may find measuring fitness per unit time more useful.

Second, for simplicity, I have assumed that which scenario a woman is in is perfectly heritable to her daughters, i.e., that the trait is stable once it emerges. This is most realistically not the case. However, the model could accommodate imperfect heritability or trait instability easily, by only changing some of the terms of the sum rather than all of them. For example, in scenario 1, some portion of the daughters could have $n+x$ children and some could continue to have $n$ children (like the sons). Or, daughters could have $n+a x$ children, where $0<a<1$. This modification may, for instance, cause the trait to take longer to reach fixation (or may prevent fixation altogether) if this model were adapted to a dynamical context. Either of these alterations - dividing fitness by time or incorporating imperfect heritability - would change the threshold conditions, so empirical researchers who find the threshold conditions useful should modify the model according to what they take to be most useful in their research context.

Before moving on, let me summarize the benefits of this model. First, the model allows us to precisely but simply delineate the substantive differences between the hypotheses covered in section 1. Second, the model allows us to compare each of these hypotheses with one another; in each case, the model generates threshold conditions which can be

\footnotetext{
${ }^{9}$ Note that one other way to enable comparison with the baseline would be to allow $x, y<0$ and $s, q<p$. These would involve grandmaternal "help" actually having a detrimental effect on their fitness, which I don't take to be particularly realistic. I therefore think that adding in parameter $t$ is a better way to accomplish comparison with the baseline.
} 
used to test the plausibility of each hypothesis over the other hypotheses. Researchers are encouraged to collect data on the relevant variables (number of offspring and their survival rate), and use that data to evaluate the threshold conditions. Third, the use of these threshold conditions may help researchers identify the most productive path forward, for instance by suggesting that certain threshold conditions (likely, the simplest ones) be evaluated first.

\section{Paternity}

This section uses an extension of the model developed in section 2 to respond to a common objection to the grandmother hypothesis.

\subsection{The objection: What about the fathers?}

Kaplan et al. (2000) suggest that, while the grandmother hypothesis is able to explain some unique features of human life history, such as a long childhood and a long lifespan compared to other primates, it fails to take into account "male support of reproduction through the provisioning of females and their offspring" (p. 156). These objectors are suggesting that grandmothers' efforts will not be needed - and, therefore, will not have been selected for - if fathers' efforts are sufficient. Their claim is based on evidence that "hunter gatherer men provide most of the energy surplus that is used to subsidize juveniles and reproductive-aged women," and that they do so via "calorie-dense, large-package, skill-intensive food resources" which go unexploited by other primates (p. 161) It makes sense that fathers, rather than grandparents, would help provide for their children, given that fathers are twice as related to their children as the grandparents are (Hrdy, 1989, p. 56). Furthermore, being able to access these protein-rich food resources both requires and helps to fuel the growth of larger brains (Sterelny, 2012, p. 84). Specialized

\footnotetext{
${ }^{10}$ One potential problem for this objection, which is not my focus in this paper, is the extent to which other primates actually do hunt and share meat (Hawkes et al., 2000, p. 246-7).
} 
hunting techniques also allowed humans to take advantage of higher latitude ecosystems, in which plant foods are rare (Kaplan et al., 2000, p. 172).

Proponents of the grandmother hypothesis, on the other hand, downplay the importance of meat due to its unreliability as a food source and its unlikelihood of being shared just with kin, rather than with the broader group (e.g., O'Connell et al., 1999, p. 478; Hawkes \& Bliege Bird, 2002, p. 59). If hunting resources are important to the overall diet but not reliable enough to keep populations alive, the importance of hunting as provisioning is in question. If hunting resources are shared more broadly, and not just with the male's offspring and mates, then it is difficult to qualify hunting as specifically reproductive effort. Additionally, some suggest "if paternal care is so critical for infant survival, fathers would be selected for paternalism, and ... sexual appetite would be selected against" (Hrdy, 1989, p. 142); in other words, the fact of male sexual promiscuity may be evidence against the importance of their role as caregivers.

Instead, in the so-called "show off hypothesis," some have suggested that hunting be viewed as mating effort (e.g., Hawkes, 1990; Hawkes, 1991; Hawkes, 2004b). Hunting, thus conceived, is a costly signal: because hunting successes are difficult to fake, they are a good way of honestly signaling skill level (Hawkes \& Bliege Bird, 2002). The men identified as more skilled will reap the benefits of having sent that signal, including a high social status, and, especially, access to more or better mates. It is an important feature of the show off hypothesis that men hunt to send a signal, not because the shared proceeds of their hunt will be reciprocated in the future (Gurven, 2004, p. 546) On this view, it's not that the nutritional value of hunting isn't important; rather, it's that its value as a signal was evolutionarily prior. Human ancestors were (evidently) able to survive by other means before they figured out how to hunt well.

Sterelny (2012) has engaged with the debate over the grandmother hypothesis, specifically by posing some problems for the show off hypothesis (p. 95-98). First, he says "it

\footnotetext{
${ }^{11}$ For a lively debate of this issue, see Gurven and Hill (2009), Hawkes, O'Connell, and Coxworth (2010), and Gurven and Hill (2010).
} 
is not obvious why hunting is differentially costly for the less expert" because hunting is a collective activity. I imagine that even hunting in a group is harder for the less fit or less skilled, however (assuming that they participate in the hunt at all - more on this below). Furthermore, the fact that hunting is a collective activity does not lessen its ability to send a signal of individual skill; think, for example, of team sports (which Sterelny himself brings up on p. 97). Second, Sterelny thinks it would be difficult to identify individual contributions to a hunt if the hunting activity was not directly witnessed by the whole group. I think that if one pictures team sports games played without an audience, it's relatively easy to explain how the wider group would come to identify contributions of the individuals: through communication with the people who did witness the game, the other team members. There may be physical evidence as well of, for instance, who dealt the decisive blow. Third, Sterelny says that if hunting were really that costly, it would be a minority activity, in which only the best would participate. To this I respond that if something as valuable as access to mates was at stake, even those who stood little to no chance of succeeding would participate (indeed, Sterelny seems to concede this point as well on p. 114). All this is just to say that the costly signaling view of men's hunting is still defensible.

Of course, the grandmother hypothesis and the alternative view, which emphasizes the contributions of men, aren't incompatible (Knight \& Power, 2005, p. 93). However, insofar as the objectors such as Sterelny do take their view to be an objection to the grandmother hypothesis, participants in this debate do take these views to be opposing. In what follows, I will be contrasting the grandmother hypothesis with the view advocated for by the "what about the fathers?" objectors, although the reader should be aware that the real explanation may not be so dichotomous.

Rather than dwell on arguments surrounding the costly signaling or provisioning explanations of men's hunting, though, I would like to redirect attention to a key difference between fathers and mothers regarding energy spent on childrearing: paternity uncertainty. 


\subsection{Paternity uncertainty explained}

Someone uncertain of their relatedness to a child will evolve corresponding motivations for being that child's allomother. For example, siblings can expect to be related by a factor of 0.5 , and half-siblings only by a factor of 0.25 . Siblings who are only $50 \%$ confident that they share the same father would act as though they are related by a factor of 0.375 (although in fact they are either related by 0.5 or 0.25 ). Similarly, while a man is actually either a child's father or not, he can expect to be related to a child by a factor of 0.5 times his credence that he is the child's father. His belief that he is the child's father may be affected by the number of other potential fathers the child has. These expected relatedness factors - as opposed to the actual relatedness - will influence the cost an individual is willing to bear in order to benefit another, including in the context of allomothering.

Paternity uncertainty affects paternal investment in children (e.g., Gaulin \& Schlegel, 1980; Apicella \& Marlowe, 2004), a phenomenon which is well-understood theoretically. For example, Trivers (1972) says, "In any society it is relatively easy to assign accurately the children to their biological mothers, but an element of uncertainty attaches to the assignment of children to their biological fathers" (p. 137), and, "The fact that in many species males are facultative polygynists ... suggests that even when monogamous the males invest less in the young than their females" (p. 143). There is an inverse relationship between paternity uncertainty and willingness to invest in (presumed) offspring (e.g., Smuts \& Gubernick, 1992), a relationship which explains the tradeoff between, on the one hand, a mating strategy which involves attempting to have as many offspring as possible and, on the other hand, a mating strategy which involves investing in extant offspring. However, it is widely assumed that human reproduction is nearly monogamous.

To explain this, one story goes that women traded exclusive sexual access to themselves as mates for men's protection and provisioning via hunting (e.g., Lancaster \& Lancaster, 1983). This led to widespread monogamous behavior, or pair-bonding. The resulting sexual "division of labor" was a result of men and women's different reproductive roles: 
"Females may target foods that do not conflict with reproduction and child care ... and males may target whichever foods females do not target" (Marlowe, 2007, p. 171). One problem with this story is that, while it may be in the female's best interest to convince the male that he has exclusive sexual access to her (given what he is compensating her with), it's still not in the female's best interest to actually give that male exclusive sexual access to her ${ }^{12}$. Thus (short of extreme measures to limit women's autonomy ${ }^{13}$ ), paternity is still not guaranteed.

Paternity uncertainty, combined with the relevant degree of relatedness, may make alloparental effort not worth it. Maternal grandmothers, on the other hand, are certain of their relationship to their grandchildren, just as mothers are certain of their relationship to their children. Recall that Hamilton's equation says that if the cost of some behavior $c<r b$ (relatedness times benefit), then that behavior is fitness-enhancing. However, if relatedness is in question, another factor, $k$, must be added, to get $c<k r b$. We can think of $k r$ as a person's known relatedness. For example, if a maternal grandfather is $k=75 \%$ sure that the daughter is his, and the daughter herself has a child (which she is sure, $k=1$, is hers), he will have a known relatedness of $0.75 \times 0.25 \approx 0.19$ to that child. Considerations of paternity uncertainty alone would predict that maternal grandmothers would invest the most in their grandchildren, followed by maternal grandfathers and paternal grandmothers (assuming equal degrees of paternity uncertainty between the maternal grandfather and his daughter and the paternal grandmother and her son's child), and finally by paternal grandfathers (Smith, 1988; Euler, 2011). Various researchers have tested this trend in differential grandparental care, often finding that a combination of paternity uncertainty and various cultural factors such as proximity to grandparents or gender roles best explains

\footnotetext{
${ }^{12}$ See Hrdy (2009 p. 153-156) for a discussion of various cultural practices that involve mothers using paternity uncertainty to elicit the support of multiple adult males. Hrdy (1989) reviews the theoretical fitness benefits of polyandry. Blurton Jones et al. (2000, p. 82) also mention the extent to which stepfathers are willing to provide for children, which must be for reasons other than their relatedness.

${ }^{13} \mathrm{~A}$ move which is not unprecedented; indeed, as Hrdy (1989) says, "Whole chapters of human history could be read as an effort to contain the promiscuity of women and thus to establish, from circumstantial evidence, the paternity that could never be proved directly (before the advent of sophisticated laboratories)" (p. 179).
} 
grandparental investment in different contexts (see especially Euler \& Weitzel, 1996, but also Pashos, 2000; Michalski \& Shackelford, 2005; Bishop, Meyer, Schmidt, \& Gray, 2009: Kaptijn, Thomese, Liefbroer, \& Silverstein, 2013; for a meta-analysis that includes reference to the grandmother hypothesis, see Strassmann \& Garrard, 2011).

Paternity uncertainty has received little attention in discussions of the potential for fathers to participate in allomaternal care. For example, Hrdy 2005, p. 297-299) recognizes several other problems with relying on paternal care (including the problems with hunting as provisioning referenced above), but does not mention paternity uncertainty ${ }^{14}$. Fathers receive a similar treatment in Hrdy (2009, p. 148-151). Blurton Jones et al. (2000) do say "Provisioning as paternal investment should vary with vulnerability of offspring and effectiveness of male care, and with male estimates of paternity" (p. 82, emphasis added), although this is in the context of female mate preference rather than that of comparing various potential allomothers.

Paternity uncertainty gets some traction with respect to paternal grandmothers (e.g., Hawkes et al., 2000, p. 249; Voland et al., 2005, p. 4; Sorenson Jamison et al., 2005, p. 100; Beise, 2005, p. 232, Leonetti et al., 2005). Paternal grandmothers can help to guarantee paternity by supervising the behavior of their son's mate. Paternal grandmothers are also known to have a positive effect on their son's mate's fitness, but often it takes the form of increasing the number of children she has, which can have negative implications for her health. This makes sense: from the perspective of the paternal grandmother's fitness, her son's mate is replaceable, even when paternity is guaranteed. Additionally, no one seems surprised that grandfathers (who are related to their grandchildren just as grandmothers are, and so, with paternity certainty, would have the same incentives to help) aren't particularly helpful; however, the explanation cited for this is that "older men have more routes by which to enhance their fitness than do postmenopausal women," because these grandfathers can themselves continue to reproduce (Blurton Jones, Hawkes, \& O'Connell,

\footnotetext{
${ }^{14}$ Later in the same article, Hrdy does say, "Because it is often difficult to know for sure which male is actually the genetic father..." but this is in the context of defending her use of "allomother" instead of "alloparent" (p. 299).
} 
2005, p. 161). I suggest that there is a much more obvious reason why grandfathers and paternal grandmothers are bad helpers: they're not sure that the grandchildren are theirs.

Paternity uncertainty can also explain the relative lack of allomaternal care from fathers, despite their high relatedness to their offspring. If paternity was guaranteed, fathers would bear the same costs for their offspring as mothers do, since $r=0.5$ for both of them. To the extent that they do not bear these same costs, it is because $k<1$ for fathers. This explains, for instance, why it doesn't make sense for a hunter to reserve all of his prey for his mate and her children: he cannot guarantee that those children are his. Instead, by sharing meat with the group, he guarantees that if he has any children in the group, they will be fed.

Additionally, paternity uncertainty explains why other potential alloparents may not find it in their best interest to help. One objection to the grandmother hypothesis, in line with the "what about fathers?" one, is "what about other relatives?" (Sterelny, 2012, p. 83-85). Older, pre-reproductive sisters provide a good example: their relatedness to the children will be, on average, 0.5 (the same as either parent, and twice as much as any grandparent), and they can benefit from learning about childcare before they have their own children. However, half-sisters are only, on average, $25 \%$ related to their younger siblings - the same as grandparents. Paternity uncertainty serves to reduce the known relatedness of a younger sibling from 0.5 to anywhere between 0.5 and 0.25. Aunts, cousins, etc. will have the same problem.

These other relatives also may be better off spending their efforts directly on their own reproductive success. Unlike post-reproductive women, other individuals need not rely on indirect benefits to kin to increase their fitness (Hrdy, 2005, p. 307). This is also true of fathers: it is widely accepted that "while the reproductive success of females will usually be limited by the number of young they can produce and raise, that of males will often be limited by factors affecting the number of females they can fertilise" (Clutton-Brock \& Harvey, 1978, p. 192; see also Trivers, 1972). Allomothering undertaken by males, then, even the father of the child, has an opportunity cost, since he could be expending that 
effort to increase his number of offspring by acquiring more mates.

\subsection{Modeling with paternity uncertainty}

This section extends the model from section 2 to accommodate paternity uncertainty. Using a formal model to examine the effect of paternity uncertainty on the relative plausibility of the "what about the fathers?" objection and the grandmother hypothesis has several benefits. First, just as in the context of comparing the grandmother hypothesis to other candidate explanations for human females' long post-reproductive lifespan, a formal analysis of the grandmother hypothesis versus a comparable hypothesis about fathers as allomothers allows us to specify exactly what each side of the debate is claiming. As we will see shortly, there is some ambiguity about what the "what about the fathers?" objectors take their objection to be claiming; I will consider two different versions. Second, and also similar to in the previous section, the formalism allows us to compare the hypotheses directly, and uncover what conditions must be met in order for one hypothesis rather than another to be more plausible. Of course, doing the actual comparison is going to require empirical data on the variables used in the model.

There is an initial question about the plausibility of allomothering behavior in fathers, referenced briefly in section 3.2. It is relatively well-known that there is a tradeoff between two mating strategies, one of which involves directing effort toward the mates and offspring you already have and the other of which involves directing a commensurate amount of effort toward acquiring more mates (and, thereby, more offspring). A very simple model can capture this tradeoff. Let $f_{0}$ be the fitnes: 4 of a father whose efforts are spent finding additional mates, and $f_{1}$ be the fitness of a father spending that same amount of effort allomothering. Both allomothering and mate-seeking can increase the number of offspring (in the former case, by reducing the interbirth interval), but mate-seeking

\footnotetext{
${ }^{15}$ For easy comparison with the other models, I am sticking with measuring fitness in number of grandchildren. This particular comparison does not require that we do so; comparisons between fathers can be made by only looking at number of children. However, the subsequent comparison between grandmothers and grandfathers will require that we use grandchildren for both fitness measures.
} 
will not affect existing offspring's survival rate. Let the survival rate of offspring for the strategy associated with $f_{0}$ be $p$ (this need not be the same value for $p$ used in the models above, although it, too, is a sort of baseline survival rate), and the additional number of offspring (above $n$ ) be $w$. The survival rate associated with $f_{1}$ will be $v$, where $v>p$, and the additional number of offspring will be $z$. In both cases, $k$ is their paternity uncertainty per child $(0<k<1)$. For simplicity, assume $k<1$ is the same for every father; $k=1$ for every mother ${ }^{16}$. The uncertainty will compound over multiple generations. For example, a grandfather can only be confident that his son's children are his grandchildren at a credence of $k^{2}$. Then we will have:

$$
\begin{gathered}
f_{0}=k\left(n_{f}+\frac{w}{2}\right) n p^{2}+k^{2}\left(n_{m}+\frac{w}{2}\right)(n+w) p^{2}=k \frac{n+w}{2}\left(n p^{2}+k(n+w) p^{2}\right) \\
f_{1}=k\left(n_{f}+\frac{z}{2}\right) n v p+k^{2}\left(n_{m}+\frac{z}{2}\right)(n+z) v^{2}=k \frac{n+z}{2}\left(n v p+k(n+z) v^{2}\right)
\end{gathered}
$$

If $w<z$, then there will be no cases where $f_{0}>f_{1}$ (allomothering fathers' fitness will be strictly better if they can both increase their number of offspring by more and have a higher offspring survival rate than mate-seeking fathers). However, if $w>z$, then $f_{0}$ can be $>f_{1}$ under certain conditions. Note that if $p \geq \frac{n+z}{n+w}$, i.e., if $w$ is sufficiently larger than $z$, then $f_{0}>f_{1}$ always. However, if $p<\frac{n+z}{n+w}$, i.e., if $w$ and $z$ are sufficiently similar, then $f_{0}>f_{1}$ only when $v<\frac{n p+p w}{n+z}$. This makes sense: it means there is an upper bound on the improvements to the offspring's survival rate that an allomothering father can have such that it would still be better for fathers to mate-seek instead.

This paper, though, is not concerned with comparisons between mating strategies for fathers, but with comparisons between fathers and grandmothers. I only bring up the comparison between $f_{0}$ and $f_{1}$ to make the following point: researchers must first

\footnotetext{
${ }^{16}$ We can always concoct situations in which $k<1$ for a mother. I will ignore these improbable situations.
} 
determine that allomothering (as opposed to mate-seeking) is a feasible strategy for males - that $f_{0}<f_{1}$ - before fathers as allomothers can be compared to grandmothers as allomothers. If allomothering is not a feasible strategy for males due to the presence of another, better strategy, one not available to grandmothers, then it will not make sense to compare grandmothers to fathers.

For the sake of this analysis, then, I will focus on the case where $f_{0}<f_{1}$ has already been established. I will now be comparing the grandmother hypothesis with two hypotheses potentially defended by the "what about the fathers?" objectors:

3. Paternal allomothering hypotheses:

(a) Higher effectiveness: Fathers are more effective as allomothers than other relatives, including maternal grandmothers.

(b) Fitness-enhancing: Fathers can enhance their fitness by acting as allomothers more than other relatives, including maternal grandmothers, can enhance theirs.

To compare the paternal allomothering hypotheses with the grandmother hypothesis, I will compare the expected number of grandchildren that a helping grandmother has (as in scenario 3 above) with the number of grandchildren that a helping father has. Comparing the grandchildren of both makes the most sense, even though the father is not directly impacting his grandchildren. Doing so does, however, eliminate the argument in favor of the paternal alloparenting hypothesis that says that it's fathers' higher relatedness to their children that makes them more likely than grandparents to help. Both helping fathers and helping grandmothers are equally related to their own grandchildren (assuming that paternity is not uncertain).

As described above, I will introduce parameter $k$ for a person's credence that particular children or grandchildren are theirs. Scenario 3 needs to be modified to take $k$ into account 
for the grandmother's son's children. Call this scenario 3', with fitness:

$$
g_{3^{\prime}}=\left(n_{f}+\frac{y}{2}\right)(n+y) s^{2}+\left(n_{m}+\frac{y}{2}\right) n k s p=\frac{n+y}{2}\left((n+y) s^{2}+n k s p\right) .
$$

The fitness of the fathers should be measured in a scenario where no helpful grandmothering is occurring, as in the baseline scenario. Instead, helping comes from the fathers, who can, like grandmothers, reduce the interbirth interval (of their mates) or increase the survival rate of their children.

First, for the higher-effectiveness version of the paternal allomothering hypothesis, assume that fathers can increase the interbirth interval and survival rate more so than grandmothers can. Fitness function $f_{1}$ above (equation 8) already describes this case, if we stipulate that $z>y$ and $v>s$. It is possible to compare $f_{2}$ with $g_{3^{\prime}}$, but the resulting inequality will have too many solutions given that both the additional number of children ( $y$ and $z$ ) and the survival rates $(r$ and $v$ ) are variable. Thus, let's use modified versions of $g_{3 a}$ and $g_{3 b}$ that incorporate paternity uncertainty for the son's children:

$$
\begin{gathered}
g_{3 a^{\prime}}=\left(n_{f}+\frac{y}{2}\right)(n+y) p^{2}+\left(n_{m}+\frac{y}{2}\right) n k p^{2}=\frac{n+y}{2}\left((n+y) p^{2}+n k p^{2}\right) \\
g_{3 b^{\prime}}=n_{f} n s^{2}+n_{m} n k s p=\frac{n}{2}\left(n s^{2}+n k s p\right)
\end{gathered}
$$

and corresponding fitnesses for fathers, $f_{1 a}$ and $f_{1 b}$ which incorporate $z>y$ or $v>s$, respectively:

$$
\begin{gathered}
f_{1 a}=k\left(n_{f}+\frac{z}{2}\right) n p^{2}+k^{2}\left(n_{m}+\frac{z}{2}\right)(n+z) p^{2}=k \frac{n+z}{2}\left(n p^{2}+k(n+z) p^{2}\right) \\
f_{1 b}=k n_{f} n v p+k^{2} n_{m} n v^{2}=k \frac{n}{2}\left(n v p+k n v^{2}\right)
\end{gathered}
$$


First, let's compare $g_{3 a^{\prime}}$ with $f_{1 a}$. In order that $g_{3 a^{\prime}}<f_{1 a}$, it must be the case that:

$$
z>\frac{1}{2} \sqrt{\frac{n(4 k(n+y)+8 y)+5 n^{2}+4 y^{2}}{k^{2}}}-\left(1+\frac{1}{2 k}\right) n .
$$

Admittedly, this lower bound on $z$ is not very intelligible; the take home message is that there is a lower bound on $z$, something greater than $y$, which was stipulated to be $<z$. (Recall that $y$ and $z$ are the additional number of offspring produced as the result of grandmaternal and paternal allomothering, respectively.) Setting $k<1$ is what generates this lower bound.

Similarly, we can compare $g_{3 b^{\prime}}$ with $f_{1 b}$. Setting $g_{3 b^{\prime}}<f_{2 b}$ yields a similarly obtuse lower bound for $v$ :

$$
v>\frac{1}{2} \sqrt{\frac{4 k p s+p^{2}+4 s^{2}}{k^{2}}}-\frac{p}{2 k}
$$

Again, the idea is that $v$ is bounded below by something greater than $s$, as a result of $k<1$ for father: 17 .

Second, for the fitness-enhancing version of the paternal allomothering hypothesis, assume that fathers are exactly as effective as grandmothers. Is this a reasonable assumption? Perhaps not; a proponent of the grandmother hypothesis may argue that grandmothers' history of being mothers may have given them unique skills in childcare and provisioning which fathers are unlikely to have acquired. However, in order to be maximally generous to the "what about the fathers?" objectors, I will assume that both parties are equally effective. In this case, we will want the allomothering effort of fathers and grandmothers (comparable to $c$ in Hamilton's equation) to be the same. Fathers will have no direct effect on their grandchildren, and their daughters will continue to only have $n$ children with the lower survival rate $p$.

In order to formulate the model such that fathers and grandmothers are expending

\footnotetext{
${ }^{17}$ In this case, $k$ is actually also restricted: there are no solutions at all unless $k>$ $\frac{1}{2} \sqrt{p^{2} s^{2}-2 p^{2} s+p^{2}+4 s^{2}}+p s-p$. In ordinary language, paternal credence $k$ has to be greater than a certain number - not just greater than 0 - for it to be at all possible that $g_{3 b^{\prime}}<f_{1 b}$.
} 
the same amount of effort, they must have a different effect on the number of offspring their mates/daughters produce. Recall from section 1 that the rationale for allomothers being able to increase the number of offspring is that they can reduce the interbirth interval by provisioning for existing offspring, thereby decreasing the time to weaning for the mother. Provisioning effort likely does not scale linearly with number of children for which one must provide, but it will increase as the number of children increases. So, it makes sense to say that if fathers and grandmothers are undertaking the same amount of provisioning effort, that they will be able to have the same effect on total number of additional offspring. The catch is that fathers will have this effect one generation earlier than grandmothers will. If grandmothers increase the number of children each of their daughters can have by $y$, then their efforts will result in a total of $y\left(\frac{y+n}{2}\right)$ total additional children to their lineage $\AA^{18}$. Fathers, then, must have that many additional children as well.

In contrast, exerting the same amount of effort with respect to survival rate will not imply, necessarily, that grandmothers must increase the survival rate of their grandchildren by less than fathers increase that of their children. I have already mentioned in section 2, in the context of comparing grandmothers to mothers, that supervision and protection of children are likely subject to highly-effective economies of scale: it does not require substantially more effort to ensure the safety of more rather than fewer children (within reason), at least not in the same way that it requires more effort to provision for the extra children. I have therefore opted to say that fathers and grandmothers who are equally effective as allomothers will have the same effect on survival rate per child under their care. Admittedly, neither of these idealizations - equal effort means equal number of additional offspring overall, and equal effort means the same effect on survival rate per child - are perfect, but they are both adequate (and, likely, justifiable in order to maintain the relative simplicity of the model).

\footnotetext{
${ }^{18}$ Note that we must restrict $n$ to be $>2-y$ in order for the number of additional children a father has to be greater than the number of additional children a grandmother's daughters each have. This will be true for all $n>2$ because $y>0$ by stipulation
} 
The relevant fitness for grandmothers here is still $g_{3^{\prime}}$. The fitness for fathers with the same effectiveness is:

$$
f_{2}=k\left(n_{f}+\frac{y^{2}+n y}{4}\right) n s p+k^{2}\left(n_{m}+\frac{y^{2}+n y}{4}\right) n s^{2}=k \frac{2 n+y^{2}+n y}{4}\left(n s p+k n s^{2}\right)
$$

Under what conditions is $g_{3^{\prime}}<f_{2}$ ? Unsurprisingly, for the fitness of the fathers to be greater than that of the grandmothers, $k$ must exceed a certain threshold (note that the square root sign extends over all three lines):

$$
\begin{array}{r}
k>\frac{2 n p y-n^{2} p y-n p y^{2}}{s\left(n y+2 n+y^{2}\right)^{2}}+\sqrt{\frac{1}{s^{2}\left(n y+2 n+y^{2}\right)^{4}}\left(n^{2} p^{2} y^{4}+2 n^{3} p^{2} y^{3}\right.} \\
\frac{-4 n^{2} p^{2} y^{3}+n^{4} p^{2} y^{2}-4 n^{3} p^{2} y^{2}+4 n^{2} p^{2} y^{2}+24 n^{2} s^{2} y^{4}+16 n^{3} s^{2} y^{3}+48 n^{2} s^{2} y^{3}+4 n^{4} s^{2} y^{2}}{\left.+48 n^{3} s^{2} y^{2}+16 n^{2} s^{2} y^{2}+16 n^{4} s^{2} y+32 n^{3} s^{2} y+16 n^{4} s^{2}+16 n s^{2} y^{5}+16 n s^{2} y^{4}+4 s^{2} y^{6}\right)}
\end{array}
$$

Given that the rather unintelligible value within the square root will be $>0$, researchers may first want to start by confirming that $k$ is greater than the first, more manageable summand of equation $17, \frac{2 n p y-n^{2} p y-n p y^{2}}{s\left(n y+2 n+y^{2}\right)^{2}}$. If it is not, then $g_{3^{\prime}}>f_{2}$, regardless of the other summand.

As in section 2, empirical researchers should take note of these thresholds for the purposes of determining whether the grandmother hypothesis - or any of the other candidate hypotheses enumerated herein - are plausible, given the evidence about our evolutionary history. The model could be extended, too, to deal with other relatives besides grandmothers and fathers. Other grandparents - paternal grandmothers and both maternal and paternal grandfathers - can be accommodated in the same way that fathers were, by counting up the number of grandchildren and applying powers of $k$ to all children related along a paternal (i.e., uncertain) line. For example, the fitness of a grandmother who only 
helped her son's children would be represented as

$$
g_{\text {pat. }}=n_{f} n p^{2}+n_{m}(n+y) k p s=\frac{n}{2}\left(n p^{2}+(n+y) k p s\right)
$$

One could compare this or other fitnesses to the maternal grandmother's fitness $g_{3^{\prime}}$. For brevity, I do not include these results in this paper.

Dealing with other relatives involves reincorporating $r$, since the fitness will not just be "downstream." Fitness will be measured in amount of one's genetic material in a given generation. The genetic contribution to a particular generation is measured by summing up the number of people in that generation, each multiplied by $r k$ (where $r$ will vary for each individual). For example, an aunt on the father's side will be confident to degree $k^{3}$ that her nieces or nephews are hers (because this will be her confidence that her father is actually her father, times her confidence that her brother is also her father's son, times her confidence that the niece/nephew is actually her brother's child), and related to that niece or nephew by $r=0.25$. When we're calculating the aunt's fitness, the term $0.25 k^{3}$ will have to be incorporated pertaining to those nieces and nephews, and other terms similarly for other relatives of their same generation. The inclusive fitness of siblings or cousins could be handled in a similar way.

The point of this section has been that the incorporation of paternity uncertainty - and the related maternity certainty - makes maternal grandmothers unique compared to anyone related to a child by some paternal relation. Due to the epistemic privilege of mothers, who are sure that her children are hers, a mother's mother is also sure that her daughters' children are her grandchildren. Other than the mother herself - whose contribution is not in question - only the maternal grandmother will be sure that her contributions to her grandchildren's welfare are contributions to the welfare of her descendants. Adding paternity uncertainty to the model from section 2 provides clear threshold conditions by which to evaluate each version of the paternal allomothering hypothesis.

\footnotetext{
${ }^{19}$ Notice that I'm returning to only using $y$ and $s$, instead of $z$ and $v$, although the latter could be easily used instead.
} 


\section{Conclusion}

The formal models provided above give researchers the tools to compare various allomothering hypotheses. By bringing paternity uncertainty to the forefront I have provided additional reason to think that maternal grandmothers - like mothers - are specially situated to contribute to reproductive efforts, compared to fathers. Any evolutionary story that relies on the reproductive contributions of men or other, not strictly maternal, relatives has to incorporate uncertainty as well as relatedness to explain why the benefits of the reproductive efforts are worth the costs. The grandmother hypothesis, unlike explanations which showcase the contributions of men, is advantaged by the fact that it doesn't have to account for this.

Recall that one reason Hrdy (2009) cites for the assumption that human societies are naturally patrilocal is "a tendency to project onto early Paleolithic ancestors patriarchal attributes from later time periods" (p. 239). I suspect that this observation applies to other assumptions as well. Knight and Power (2005) provide evidence that monogamy and nuclear families were insisted to be fundamental throughout the 20th century because the opposite - that matrilineal and matrilocal social organization was common - was associated with Communism (p. 82-87). This ideological inheritance may still have effects today, where, as far as I've found, discussions of male contributions tend to assume that paternity, since it is (nearly) guaranteed by monogamous marital relations, will not be uncertain.

Proponents of the grandmother hypothesis have also noticed a tendency to underestimate the productivity of women. Hrdy (2005) recounts how an ethnographer dismissed an older woman as a "nuisance," and "physically quite revolting"; Hrdy says that because "anthropologists and evolutionists alike - most of them males - assumed the function of women was to bear and rear children ...p postreproductive women seemed irrelevant" (p. 295-296). For example, the claim that "scavenged brains and bone marrow are the most plausible source of protein, and such scavenging is unlikely to be a grandmaternal 
specialty" (Sterelny, 2012, p. 84) goes unsubstantiated. Hawkes and Bliege Bird (2002) note that two assumptions underly the theory that men's hunting was essential to human evolutionary success: "that such hunting is part of the most efficient energy or protein maximization strategy and that such hunting is inefficient when attempted by women" (p. 59). Hrdy (1989) wonders "why - if intelligence evolved among males to help them hunt - Nature should have squandered it on a sex that never hunted" (p. 5), and references evidence from primatology that "females participate as much as males, or more, in defending feeding areas" (p. 73). Research that maintained an open mind to the nutritional resources and defense from predation that women, including grandmothers, can provide may find that their specialties aren't relegated to gathering and processing plant foods and tending young children. For example, Bliege Bird and Codding (2015) argue that the "traditional" division of labor between men as hunters and women as gatherers is only one of many common arrangements in human groups. Researchers may well find, for instance, that the fitness-enhancing version of the paternal allomothering hypothesis is unsupported by the data, not because the threshold conditions I have identified are not met, but because the assumption that fathers and grandmothers are equally effective may be unrealistic. I think it is highly plausible that grandmothers are simply better equipped to be allomothers than fathers are.

This paper contributes to literature in the philosophy of science in two ways. First, the model developed in this paper, and especially the inclusion of paternity uncertainty, can serve as a formal and conceptual tool for empirical researchers who are looking to make progress in the debate about the plausibility of the grandmother hypothesis. It is not usually the role of philosophers of science to settle these debates directly; rather, it is our role to provide guidance to scientists. In this case, that guidance has taken the form of an analytical model, and a justification for using it. The model is intended to help researchers - anthropologists, evolutionary biologists, and primatologists alike - first, to have access to a rigorous, formal presentation of the various candidate hypotheses in order to aid in framing the debate; second, to know which variables we require data for in order to make 
progress at settling that debate; and third, to know how to use these data to compare and evaluate hypotheses which seek to explain the longevity of human females. A second way in which this paper contributes to the philosophy of science literature is by extending the feminist philosophy of science literature on the role of females in human evolution. This paper does so by highlighting both an evolutionary puzzle that is particular to women why did menopause evolve? - and emphasizing a unique feature of females, namely their maternity certainty. Investigating these questions has the potential to reframe and revise how we think about humans' evolutionary past. 


\section{References}

Alvarez, H. P. (2000). Grandmother hypothesis and primate life histories. American Journal of Physical Anthropology, 113, 435-450.

Anderson, E. (1995). Feminist epistemology: An interpretation and a defense. Hypatia, $10(3), 50-84$.

Apicella, C. L., \& Marlowe, F. W. (2004). Perceived mate fidelity and paternal resemblance predict men's investment in children. Evolution and Human Behavior, 25 (6), 371-378.

Beise, J. (2005). The helping and helpful grandmother: The role of maternal and paternal grandmothers in child mortality in the seventeenth- and eighteenth-century population of French setlers in Quebec, Canada. In E. Voland, A. Chasiotis, \& W. Schiefenhovel (Eds.), Grandmotherhood: The evolutionary significance of the second half of female life (p. 215-238). Piscataway, NJ: Rutgers University Press.

Bishop, D. I., Meyer, B. C., Schmidt, T. M., \& Gray, B. R. (2009). Differential investment behavior between grandparents and grandchildren: The role of paternity uncertainty. Evolutionary Psychology, 7(1).

Bleier, R. (1984). Science and gender: A critique of biology and its theories on women. New York, NY: Pergamon Press.

Bliege Bird, R., \& Codding, B. F. (2015). The sexual division of labor. In R. Scott \& S. Kosslyn (Eds.), Emerging trends in the social and behavioral sciences. Hoboken, NJ: John Wiley and Sons.

Blurton Jones, N., Hawkes, K., \& O’Connell, J. (2005). Hadza grandmothers as helpers: Residence data. In E. Voland, A. Chasiotis, \& W. Schiefenhovel (Eds.), Grandmotherhood: The evolutionary significance of the second half of female life (p. 160-176). Piscataway, NJ: Rutgers University Press.

Blurton Jones, N., Marlow, F. W., Hawkes, K., \& O’Connell, J. F. (2000). Paternal investment and hunter-gatherer divorce rates. In L. Cronk, N. Chagnon, \& W. Irons 
(Eds.), Adaptation: An anthropological perspective (p. 69-90). Hawthorne, New York: Walter de Gruyter, Inc.

Caspari, R., \& Lee, S. (2004). Older age becomes common late in evolution. Proceedings of the National Academy of Sciences, 101 (30), 10895-10900.

Chan, M. H., Hawkes, K., \& Kim, P. S. (2016). Evolution of longevity, age at last birth and sexual conflict with grandmothering. Journal of Theoretical Biology, 393, $145-157$.

Charnov, E. L. (1993). Life history invariants: Some explorations of symmetry in evolutionary ecology. Oxford, UK: Oxford University Press.

Clutton-Brock, T. H., \& Harvey, P. H. (1978). Mammals, resources, and reproductive strategies. Nature, 273, 191-195.

Euler, H. A. (2011). Grandparents and extended kin. In The Oxford handbook of evolutionary family psychology. doi: 10.1093/oxfordhb/9780195396690.013.0012

Euler, H. A., \& Weitzel, B. (1996). Discriminative grandparental solicitude as reproductive strategy. Human Nature, 7(1), 39-59.

Fausto-Sterling, A. (1992). Myths of gender: Biological theories about women and men (2nd ed.). New York, NY: Basic Books.

Gaulin, S. J. C., \& Schlegel, A. (1980). Paternal confidence and paternal investment: A cross cultural test of a sociobiological hypothesis. Ethology and sociobiology, 1(4), 301-309.

Gurven, M. (2004). To give and to give not: The behavioral ecology of human food transfers. Behavioral and Brain Sciences, 27, 543-583.

Gurven, M., \& Hill, K. (2009). Why do men hunt? A reevaluation of "man the hunter" and the sexual division of labor. Current Anthropology, 50(1), 51-74.

Gurven, M., \& Hill, K. (2010). Moving beyond stereotypes of men's foraging goals: Reply to Hawkes, O'Connell, and Coxworth. Current Anthropology, 51(2), 265-267.

Hamilton, W. D. (1964). The genetical evolution of social behaviour. Journal of Theoretical Biology, 7(1), 1-16. 
Hawkes, K. (1990). Why do men hunt? benefits for risky choices. In E. Cashdan (Ed.), Risk and uncertainty in tribal and peasant economies (p. 145-166). Westview.

Hawkes, K. (1991). Showing off: Tests of an hypothesis about men's foraging goals. Ethology and Sociobiology, 12, 29-54.

Hawkes, K. (2003). Grandmothers and the evolution of human longevity. American Journal of Human Biology, 15, 380-400.

Hawkes, K. (2004a). The grandmother effect. Nature, 428, 128-129.

Hawkes, K. (2004b). Mating, parenting, and the evolution of human pair bonds. In B. Chapais \& C. M. Berman (Eds.), Kinship and behavior in primates (p. 443-473). New York, NY: Oxford University Press.

Hawkes, K. (2016). Genomic evidence for the evolution of human postmenopausal longevity. Proceedings of the National Academy of Sciences (USA), 113(1), 17-18.

Hawkes, K., \& Bliege Bird, R. (2002). Showing off, handicap signaling, and the evolution of men's work. Evolutionary Anthropology, 11, 58-67.

Hawkes, K., \& Blurton Jones, N. (2005). Human age structures, paleodemography, and the grandmother hypothesis. In E. Voland, A. Chasiotis, \& W. Schiefenhovel (Eds.), Grandmotherhood: The evolutionary significance of the second half of female life (p. 118-140). Piscataway, NJ: Rutgers University Press.

Hawkes, K., O'Connell, J., \& Blurton Jones, N. (2018). Hunter-gatherer studies and human evolution: A very selective review. American Journal of Physical Anthropology, $165,777-800$.

Hawkes, K., O’Connell, J. F., \& Blurton Jones, N. G. (1989). Hardworking Hadza grandmothers. In V. Standen \& R. A. Foley (Eds.), Comparative socioecology: The behavioural ecology of humans and other mammals (p. 341-366). London, UK: Blackwell Scientific Publications.

Hawkes, K., O’Connell, J. F., Blurton Jones, N. G., Alvarez, H., \& Charnov, E. L. (1998). Grandmothering, menopause, and the evolution of human life histories. Proceedings of the National Academy of Sciences of the United States of America, 95(3), 1336- 
1339.

Hawkes, K., O’Connell, J. F., Blurton Jones, N. G., Alvarez, H., \& Charnov, E. L. (2000). The grandmother hypothesis and human evolution. In L. Cronk, N. Chagnon, \& W. Irons (Eds.), Adaptation: An anthropological perspective (p. 237-258). Hawthorne, New York: Walter de Gruyter, Inc.

Hawkes, K., O'Connell, J. F., \& Coxworth, J. E. (2010). Family provisioning is not the only reason men hunt: A comment on Gurven and Hill. Current Anthropology, $51(2), 259-264$

Hawkes, K., \& Smith, K. R. (2010). Do women stop early? Similarities in fertility decline in humans and chimpanzees. Annals of the New York Academy of Sciences, 1204, $43-53$.

Herndon, J. G. (2009). The grandmother effect: Implications for studies on aging and cognition. Gerontology, 56, 73-79.

Hrdy, S. B. (1989). The woman that never evolved (2nd ed.). Cambridge, MA: Harvard University Press.

Hrdy, S. B. (2005). Cooperative breeders with an ace in the hole. In E. Voland, A. Chasiotis, \& W. Schiefenhovel (Eds.), Grandmotherhood: The evolutionary significance of the second half of female life (p. 295-317). Piscataway, NJ: Rutgers University Press.

Hrdy, S. B. (2009). Mothers and others: The evolutionary origins of mutual understanding. Cambridge, MA: Harvard University Press.

Huber, S., \& Fieder, M. (2018, September). Evidence for a maximum "shelf-life" of oocytes in mammals suggests that human menopause may be an implication of meiotic arrest. Scientific Reports, 8(1), 14099. doi: 10.1038/s41598-018-32502-2

Johnstone, R. A., \& Cant, M. A. (2010). The evolution of menopause in cetaceans and humans: the role of demography. Proceedings of the Royal Society B, 27r, 3765-3771.

Kachel, A. F., Premo, L. S., \& Hublin, J. (2011). Grandmothering and natural selection. 
Proceedings of the Royal Society B, 278, 384-391.

Kaplan, H. (1994). Evolutionary and wealth flows theories of fertility: Empirical tests and new models. Population and development reviews, 20, 753-791.

Kaplan, H., Hill, K., Lancaster, J., \& Hurtado, A. M. (2000). A theory of human life history evolution: Diet, intelligence, and longevity. Evolutionary Anthropology, 89, 156-184.

Kaptijn, R., Thomese, F., Liefbroer, A. C., \& Silverstein, M. (2013). Testing evolutionary theories of discriminative grandparental investment. Journal of Biosocial Science, 45(3), 289-310.

Keller, E. F. (1992). Secrets of life, secrets of death: Essays on science and culture. New York, NY: Routledge.

Kim, P. S., Coxworth, J. E., \& Hawkes, K. (2012). Increased longevity evolves from grandmothering. Proceedings of the Royal Society B: Biological Sciences, 279(1749), 4880-4884.

Kim, P. S., McQueen, J. S., Coxworth, J. E., \& Hawkes, K. (2014). Grandmothering drives the evolution of longevity in a probabilistic model. Journal of Theoretical Biology, 353, 84-94.

Kim, P. S., McQueen, J. S., \& Hawkes, K. (2019). Why does women's fertility end in mid-life? grandmothering and age at last birth. Journal of theoretical biology, 461, $84-91$.

Knight, C., \& Power, C. (2005). Grandmothers, politics, and getting back to science. In E. Voland, A. Chasiotis, \& W. Schiefenhovel (Eds.), Grandmotherhood: The evolutionary significance of the second half of female life (p. 81-98). Piscataway, NJ: Rutgers University Press.

Lancaster, J. B., \& Lancaster, C. (1983). Parental investment: the hominid adaptation. In D. J. Ortner (Ed.), How humans adapt: Biocultural odyssey (p. 33-56). Washington, DC: Smithsonian Institution Press.

Leonetti, D. L., Nath, D. C., Hemam, N. S., \& Neill, D. B. (2005). Kinship organization 
and the impact of grandmothers on reproductive success among the matrilineal Khasi and patrilineal Bengali of northeast India. In E. Voland, A. Chasiotis, \& W. Schiefenhovel (Eds.), Grandmotherhood: The evolutionary significance of the second half of female life (p. 194-214). Piscataway, NJ: Rutgers University Press.

Mace, R., \& Sear, R. (2005). Are humans cooperative breeders? In E. Voland, A. Chasiotis, \& W. Schiefenhovel (Eds.), Grandmotherhood: The evolutionary significance of the second half of female life (p. 143-159). Piscataway, NJ: Rutgers University Press.

Marlowe, F. W. (2007). Hunting and gathering: The human sexual division of foraging labor. Cross-Cultural Research, 41(2), 170-195.

Michalski, R. L., \& Shackelford, T. K. (2005). Grandparental investment as a function of relational uncertainty and emotional closeness with parents. Human Nature, 16(3), 293-305.

O'Connell, J. F., Hawkes, K., \& Blurton Jones, N. G. (1999). Grandmothering and the evolution of Homo erectus. Journal of Human Evolution, 36, 461-485.

Paquin, D., Kato, D., \& Kim, P. (2020). A mathematical model for the effects of grandmothering on human longevity. Mathematical Biosciences and Engineering, 17 (4), 3175-3189. doi: 10.3934/mbe.2020180

Pashos, A. (2000). Does paternal uncertainty explain discriminative grandparental solicitude? a cross-cultural study in greece and germany. Evolution and Human Behavior, $21(2), 97-109$.

Paul, A. (2005). Primate predispositions for human grandmaternal behavior. In E. Voland, A. Chasiotis, \& W. Schiefenhovel (Eds.), Grandmotherhood: The evolutionary significance of the second half of female life (p. 21-37). Piscataway, NJ: Rutgers University Press.

Peccei, J. S. (2001). A critique of the grandmother hypotheses: Old and new. American Journal of Human Biology, 13, 434-452.

Peccei, J. S. (2005). Menopause: Adaptation and epiphenomenon. In E. Voland, A. Cha- 
siotis, \& W. Schiefenhovel (Eds.), Grandmotherhood: The evolutionary significance of the second half of female life (p. 38-58). Piscataway, NJ: Rutgers University Press.

Smith, M. S. (1988). Research in developmental sociobiology: Parenting and family behavior. In K. B. MacDonald (Ed.), Sociobiological perspectives on human development (pp. 271-292).

Smuts, B. B., \& Gubernick, D. J. (1992). Male-infant relationships in nonhuman primates: Paternal investment or mating effort? In B. S. Hewlett (Ed.), Father-child relations: Cultural and biosocial contexts (p. 1-30). New York, NY: Routledge.

Sorenson Jamison, C., Jamison, P. L., \& Cornell, L. L. (2005). Human female longevity: How important is being a grandmother? In E. Voland, A. Chasiotis, \& W. Schiefenhovel (Eds.), Grandmotherhood: The evolutionary significance of the second half of female life (p. 99-117). Piscataway, NJ: Rutgers University Press.

Sterelny, K. (2012). The evolved apprentice: How evolution made humans unique. Cambridge, MA: MIT Press.

Strassmann, B. I., \& Garrard, W. M. (2011). Alternatives to the grandmother hypothesis: A meta-analysis of the association between grandparental and grandchild survival in patrilineal populations. Human Nature, 22(1), 201-222.

Trivers, R. L. (1972). Parental investment and sexual selection. In B. Campbell (Ed.), Sexual selection and the descent of man 1871-1971. Chicago, IL: Aldine Publishing Company.

Voland, E., Chasiotis, A., \& Schiefenhovel, W. (2005). Grandmotherhood: A short overview of three fields of research on the evolutionary significance of postgenerative female life. In E. Voland, A. Chasiotis, \& W. Schiefenhovel (Eds.), Grandmotherhood: The evolutionary significance of the second half of female life (p. 1-17). Piscataway, NJ: Rutgers University Press.

Ward, E. J., Parsons, K., Holmes, E. E., Balcomb, K. C., \& Ford, J. K. B. (2009). The role of menopause and reproductive senescence in a long-lived social mammal. 
Frontiers in Zoology, 6(4).

West, S. A., Griffin, A. S., \& Gardner, A. (2007). Evolutionary explanations for cooperation. Current Biology, 17(16), R661-R672. doi: 10.1016/j.cub.2007.06.004

Williams, G. C. (1957). Pleiotropy, natural selection, and the evolution of senescence. Evolution, 11(4), 398-411. 